\title{
THE COST OF RIGHT-OF-WAY ACQUISITION: RECOGNIZING THE IMPACT OF CONDEMNATION VIA A SWITCHING REGRESSION MODEL
}

\author{
Xiaoxia Xiong \\ The University of Texas at Austin \\ 1.120. Cockrell Jr. Hall \\ Austin, TX 78712-1076 \\ xiaoxia.xiong@utexas.edu \\ Kara M. Kockelman \\ (Corresponding author) \\ Professor and William J. Murray Jr. Fellow \\ Department of Civil, Architectural and Environmental Engineering \\ The University of Texas at Austin \\ 6.9 E. Cockrell Jr. Hall \\ Austin, TX 78712-1076 \\ kkockelm@mail.utexas.edu \\ Phone: 512-471-0210 \\ FAX: $512-475-8744$
}

The following is a pre-print and the final publication can be found in the Journal of Infrastructure Systems, Volume 20 (4), 2014.

\begin{abstract}
The costs of acquiring parcels by condemnation are usually significantly higher than those for property acquired by negotiation, suggesting that the Right-of-Way $(\mathrm{R} / \mathrm{W})$ acquisition costs may best be described by two different regression equations. This paper develops a switching regression model of acquisition cost to simultaneously predict the probability of whether a parcel will go to condemnation rather than be acquired via negotiation and the corresponding acquisition costs under these two regimes. The error terms of the selection equation and the two cost equations follow a trivariate normal distribution to reflect co-dependence on unobserved factors (such as a land owner's tenacity or a site's view value).

When applied to the properties acquired across the state of Texas for transportation probjects between 2008 and 2011, results of this switching regression model suggest that R/W appraisers and staff should pay special attention to parcels in commercial use involving a partial taking with a relatively small remainder and located in more urbanized areas. Comparison of cost estimates between the two regimes (condemnation vs. negotiation) suggests that condemned parcels will have, on average, $78 \%$ higher acquisition costs across the 1,710 acquired properties and $51 \%$ greater price variation. These results suggest that it is much more costly to acquire a property and more difficult to accurately predict its costs if it cannot be acquired via negotiation. The application of model estimates to an example corridor highlights the value of simulation to capture all modeling uncertainties.
\end{abstract}

Key words: Right of Way Acquisition, Cost Estimation, Condemnation, Endogenous Switching Regression 


\section{BACKGROUND AND MOTIVATION}

Public construction projects often require that government agencies acquire real property (real estate or some interest therein) (FHWA, 2011). In the case of travel corridors, a desired property can typically be acquired via either negotiation (including administrative settlement and other negotiation options) or condemnation (such as a commissioners hearing and a court trial) ${ }^{1}$ (FHWA, 2009). Transportation agencies are required to "expedite acquisition, avoid litigation, and establish confidence in federal land acquisition practices", so condemnation proceedings will not be initiated unless negotiation fails (FHWA, 2010).

"Just compensation" (based on properties' fair market values) must be paid under federallyfunded programs and projects (FHWA, 2002). These compensation fees, as well as other costs associated with R/W acquisition (e.g., utility relocation and relocation assistance), can be very expensive. FHWA data for fiscal year 2010 shows that the federal government spent approximately $\$ 1.5$ billion (or $\$ 67,200$ per taking) on properties acquired, with an extra $\$ 26$ million and $\$ 45$ million on residential and non-residential displacements, respectively (FHWA, 2011a). Approximately $20 \%$ of these takings were settled by condemnation, and this percentage is higher in states like Florida (42.9\% between 1991 and 1994) where property owners' legal fees are paid by the acquiring agencies (FHWA, 2011b). The condemnation proceeding can add significantly to acquisition and administrative costs (including attorney fees and court costs) and result in significant time delays attributed to the additional stages in the condemnation process. For example, between 2006 and 2010, condemnation awards added an average of 35.3 to $98.7 \%$ to the Texas Department of Transportation (TxDOT)'s initial approved value for purchasing a parcel (Caldas et al., 2011). Parcels acquired through condemnation in Texas' Austin district also have on average 8month lengthier acquisition periods between 2005 and 2009 (Le, 2009). These delays in acquisitions can also result in project cost escalation, due to the effects of inflation (Anderson, 2009). Accurate prediction of a parcel's acquisition type (negotiation vs. condemnation) and attendant costs are useful for project budgeting and completion.

This paper develops an endogenous switching regression model to anticipate whether condemnation is likely and to estimate acquisition costs (as paid to property owners, which is less than full costs), recognizing the fact that negotiated parcels and condemned parcels involve distinct acquisition procedures (e.g., administrative settlement vs. court trial), and that the cost differences across these two regimes are usually significant. Simpler methods such as least-squares models (Buffington et al., 1995; Heiner and Kockelman, 2005; Kockelman et al., 2006) and binary logistic models (Hakimi and Kockelman, 2005; Kades, 2008) have already been used in R/W cost estimation and for condemnation rates across U.S. states, respectively. The following describes such model applications for $\mathrm{R} / \mathrm{W}$ acquisition, along with use of switching regression models in other contexts.

\section{Condemnation Rates}

FHWA representatives report several types of parcels that are typically anticipated to go to condemnation (Caldas et al., 2011): commercial properties usually have higher condemnation rates because they contain expensive improvements and their parking spaces, access points and internal traffic patterns are often affected by $\mathrm{R} / \mathrm{W}$ acquisition; access rights only parcels (especially with restricting access to only right-in right-out) are also very common in condemnation; parcels that involve partial takings are also more likely to result in litigation since such acquisitions usually lead to disputes over the price of damages to remainders ${ }^{2}$ between the property owners and acquiring agencies. The representatives also indicate that property owners' occupation, personal emotions

\footnotetext{
${ }^{1}$ It should be noted that as soon as a condemnation action is filed, the possession type is classified as condemnation no matter how the case is later settled (e.g., some cases could have been settled prior to court awards) (FHWA, 2009).

${ }^{2} \mathrm{~A}$ remainder is the portion of the property which is not acquired by the agency in the case of partial taking (FHWA, 2002).
} 
towards the project, and emotional ties to their properties can also play a role in cause for condemnation.

Hakimi and Kockelman (2005) compared state condemnation statutes and found that statutes on compensable items, uneconomic remnants, quick and early takings, land consolidation, and land exchange can significantly impact condemnation rates nationwide. Their logistic model of state condemnation rates suggests that more urbanized states with higher education attainment and Republican party affiliation have higher rates of condemnation after controlling for other state characteristics such as the share of federally owned land and total rural highway mileage per capita. Similarly, Kades (2008) found that the presence of water and hills (geography), high density of population, and fee-shifting statutes offer statistically significant explanatory power in condemnation rates nationwide. Caldas et al. (2006) employed descriptive statistics to analyze the probability of condemnation at the parcel level and identified five influential factors: project type (e.g., interchange vs. freeway widening), land use type, taking type (whole or partial), existence of improvements, and parcel location. However, they were unable to obtain sufficient $\mathrm{R} / \mathrm{W}$ data to establish regression models.

\section{Cost Estimation}

Accurate R/W cost estimates are usually difficult to obtain due to various uncertainties (especially in appraisal and damages from partial takings) (Anderson, 2009). Formal property appraisals can play an important role in determining the final costs of $\mathrm{R} / \mathrm{W}$ acquisition (Heiner and Kockelman, 2005), because inaccurate appraisals can undermine public trust in federal land acquisition practices while increasing the odds of condemnation and incidental costs (e.g., legal costs and staff time). Unfortunately, appraisals can be far from true market valuations due to incomplete data access and collection and/or subjective biases and other limitations on the part of appraisers. State laws $^{3}$ and other distinguishing features (such as environmental, social, and political characteristics), project and parcel complexity, as well as human factors affecting the interaction between the property owners and agencies also affect overall acquisition costs (Anderson, 2009).

Hedonic price models are widely used for price estimation, typically employing leastsquares regression and decomposing property values into land and improvement. Property location variables (such as proximity to highways and local school quality indices) are almost always included to characterize the value of land (Bina and Kockelman, 2009; Gelfand et al., 2004; Wilhelmsson, 2000). For example, Iacono and Levinson (2009) studied the impacts of highway construction and capacity expansion on property values. Their results for Hennepin, Minnesota suggest that homes within one mile of upgraded highways were negatively impacted, while their sales price were estimated to fall by $1.2 \%$ for every $1 / 4$ mile from the nearest access points. Peiser (1987) examined non-residential urban land values using sales transactions between 1978 and 1982 in Dallas, Texas. He found that a corner location for industrial land carried approximately $46 \%$ higher value than a middle-block location, while frontage on a major arterial and expressway was estimated to add $43 \%$ and $68 \%$ to industrial land values, respectively, relative to that on a minor street. He also estimated that distance to CBD had greater impact on the value of office land than on commercial land, and no significant effect on industrial land. Abelson (1997) found that home prices and distance to CBD generally followed a negative exponential relationship in Sydney, Australia from 1931 to 1989.

Importantly, this rich literature on property valuation does not address public takings. In recent years, 90 to 95 percent of state DOT acquisitions in Texas and Pennsylvania were partial takings (Caldas et al., 2011), usually involving relatively complex contexts - such as split and irregularly-shaped remainders, changes in highest and best property uses, and diminished access.

${ }^{3}$ For example, since the case of Kelo v. City of New London (2005), some states have enacted laws that provideproperty owners with additional payments in acquisition and/ or relocation beyond the Uniform Act requirements (including "supercompensation" payments that are based on $100 \%$ of fair market value plus a certain percentage [e.g., $25 \%$ for homestead taking and $50 \%$ for heritage taking in Missouri]) (FHWA, 2007). 
Heiner and Kockelman (2005) developed a model of acquisition costs for properties along Texas corridors. Taken area, remainder area and improved square footage were interacted with variables like year of acquisition, land use type, and parcel location (by county) to reflect unit costs on land and improvements. Their results suggest that retail uses carried the greatest acquisition costs, per acre. Locations, the taking of any improvements, and damages to remainders (especially a change in the parcel's highest and best use, but also a change in shape or reduction of parcel frontage) were very practically (and statistically) significant. However, they did not account for cost differentials that emerge between negotiated and condemned properties. Buffington et al. (1995) examined the effects of remainders on acquisition costs in Texas using least-squares regression and found similar variables to be important. Several access-rights cost studies also exist, using either least-squares regression or descriptive statistics (e.g., Gallego [1996], Kockelman et al. [2003], and Westerfield [1993]).

Various tools have been developed to assist planning level R/W cost estimation, such as Virginia DOT's Project Cost Estimation System (PCES) (which estimates all project-related costs) (VDOT, 2005) and Georgia DOT's ROW and Utility Estimation Tool (RUCEST) (GDOT, 2007). Kockelman et al. (2006) developed a spreadsheet-based R/W cost estimation tool for TxDOT to assist engineers and planners in project feasibility analysis. In addition to generating least-squares regression estimates of parcel-by-parcel costs, the tool provides average unit costs for comparable parcels (as available in thousands of past-project records). Krugler et al. (2010) designed a program named "TAMSIM" to simulate R/W acquisition process utilized by TxDOT, with acquisition costs specified using lognormal distributions for Texas metropolitan, urban, and rural areas (based on regional population).

\section{Switching Regression Model Applications}

Switching models are widely used in contexts with two or more regression equations to describe the behavior of distinct agents or settings (Maddala 1983), such as Lee's (1978) union-nonunion wage model and Trost's (1977) housing-demand model (for owner-occupied vs. rental housing). Such models have two levels, to decide which regime an observational unit falls into (based on one or more latent state variables), and to describe the behaviors in each regime. Generally, switching regression models can be divided into several types based on the nature of the data: with sample separation known or unknown (i.e., observed or unobserved regimes) and with endogenous or exogenous switching (i.e., with or without correlation across the two model levels) (Maddala, 1986). In the $\mathrm{R} / \mathrm{W}$ acquisition context, a switching regression with known sample separation and endogenous switching makes the best sense ${ }^{4}$. This functional specification is provided later in the paper. Such models have been used in other transportation contexts, but not in R/W acquisition. For example, Abdelwahab and Sargious (1991) estimated freight mode choice (truck vs. rail) and corresponding shipment size. Meurs (1993) modeled household car ownership and trip generation (for 0-vehicle, 1-vehicle and 2-or-more-vehicle households) using panel data. Bhat (1993) modeled wife's employment status and household car ownership (for wife-employed vs. wife-unemployed households).

To date, no published model has analyzed condemnation likelihoods at the level of individual properties/parcels. Such models can help determine which parcels carry higher risk of condemnation, along with ultimate project costs, while allowing for correlation in unobserved components (across the model's two stages). As noted earlier, parcels taken by condemnation tend to entail significantly higher acquisition costs than those obtained via negotiation (Caldas, et al., 2011), and a two-regime model allows for a variety of differences in property cost relationships, while leaving the condemnation outcome naturally endogenous to the model. The following

\footnotetext{
${ }^{4}$ This is because the R/W cost sample can be segmented into two observed regimes (condemnation and negotiation) and the cost of a certain parcel should correlate with its acquisition type due to several latent attributes.
} 
sections describe the data used to operationalize such a model for property acquisitions by TxDOT, the model's specification, and all results obtained.

\section{DATA ASSEMBLY}

The sample used for the switching-model's estimation was exported from TxDOT's Right of Way Information Systems (ROWIS), for all 2,380 acquisitions occurring between September 1 of 2008 and January 14 of 2011, covering 81 (out of 254) Texas counties. Only data records (parcels) with both "acquisition type" (condemnation or negotiation) and "total amount paid" values were viable for use here. Other possession methods - such as through donations, option to purchase, or local public agency acquisition - were not included in the analysis since these represent only $5.3 \%$ of the total. Access-rights-only parcels were also dropped because the amount of land affected or "taken" (for access purposes) was not available. Finally, some parcel records were of questionable use, since their settlement type and possession type were recorded inconsistently (e.g., "administrative settlement" showed in the "Settlement type" column but "condemnation" appeared in the "Possession type" column). Dropping all of these parcels yielded a final sample of 1,710 parcels for model estimation here.

ROWIS provides information on each taking's "total" acquisition cost (rather than land and improvements separately), acquisition type and parcel characteristics (e.g., size, county, land use type, and ownership type). Details on the nature and size of improvements taken or presence and magnitude of damages caused to remainders are not available in the database, so such attributes are not controlled for here. It should be noted that acquisition costs include only the amount paid to the original property owners for land, improvements (if taken), and damages caused to the reminder (as offered by the DOT and accepted by the property owner or as determined in a court of law); it does not include the value of other costs involved in the acquisition process (e.g., appraisal fees, relocation assistance, attorneys' fees, and project-delay costs, to the extent these exist). Dollar values were adjusted for inflation using the U.S. Consumer Price Index (BLS 2011), to arrive at January 2011 dollars. Table 1 provides descriptions and associated statistics for all variables used.

\section{MODEL SPECIFICATION}

Maddala and Nelson's (1975) endogenous-switching regression model (as described in Maddala [1983]) was used here, to predict the probability of a parcel being acquired via negotiation or condemnation, and the corresponding acquisition costs under these two regimes. Such models allow for correlation in unobserved attributes between acquisition type and acquisition payment (e.g., a sophisticated land owner lobbying for higher payment and more likely to take the case to court, or an oddly shaped parcel fetching a lower appraisal [and DOT offer] but also requiring a more complicated legal process to support the value assessment). The model can be written as follows:

If $\gamma^{\prime} Z_{i}+u_{i}>0$, parcel $i$ will go to condemnation, with Condemn $n_{i}=1$.

If $\gamma^{\prime} Z_{i}+u_{i} \leq 0$, parcel $i$ will go to negotiation, with Condemn $_{i}=0$.

If Condemn $_{i}=1$, acquisition cost $Y_{1 i}=x_{1 i}^{\prime} \beta_{1}+\varepsilon_{1 i}$.

If Condemn $_{i}=0$, acquisition cost $Y_{2 i}=x_{2 i}^{\prime} \beta_{2}+\varepsilon_{2 i}$.

In this model, $Z_{i}$ is a vector of parcel $i$ 's characteristics that affect whether the property will go to condemnation or be acquired via negotiation. These include attributes like parcel location and land use type, parcel size, taking type (partial vs. whole taking) and ownership type (e.g., individual versus corporate owner). Vectors $x_{1 i}$ and $x_{2 i}$ are parcel characteristics affecting acquisition cost (e.g., a time trend variable for the year of acquisition, population density of the local area, land use type, taking type, and remainder area). Improvement attributes (such as building square footage 
variables) were not controlled for here since these are not made available in ROWIS. $Y_{1 i}$ and $Y_{2 i}$ are the dependent variables for acquisition costs (total paid to property owners) under the two regimes (but observed only in one regime for each acquired property). Vectors of parameters to be estimated are $\gamma, \beta_{1}$ and $\beta_{2}$, along with correlations in the cross-equation covariance matrix (as described below). The error terms $(\varepsilon)$ represent unobserved attributes that affect outcomes, which could include any odd shape or severe slope of the parcel, more specific land use types (e.g., gas station or restaurant), and parcel location details (such as mid-block or corner).

Here, the natural-log transformation of acquisition costs $(Y)$ and land area variables (TakenSF and RemainderSF) were used to ensure the non-negativity of cost estimates while dampening rightward skew of the cost data. The model assumes that the three random error terms $\left(u_{i}, \varepsilon_{1 i}\right.$ and $\left.\varepsilon_{2 i}\right)$ follow a trivariate normal distribution with a mean vector of zeros and the following covariance matrix:

$$
\Omega=\left[\begin{array}{ccc}
\sigma_{u}^{2} & \sigma_{1 u} & \sigma_{2 u} \\
\sigma_{1 u} & \sigma_{1}^{2} & \mathrm{n} / \mathrm{a} \\
\sigma_{2 u} & \mathrm{n} / \mathrm{a} & \sigma_{2}^{2}
\end{array}\right]
$$

The covariance terms between $\varepsilon_{1 i}$ and $\varepsilon_{2 i}$ are not defined (n/a) since properties are never acquired both by condemnation and negotiation. The first variance $\sigma_{u}^{2}$ is normalized to one to ensure statistical identification of parameters. The model can be estimated by the full information maximum likelihood (FIML) procedure, with observation $i$ 's likelihood written as follows ${ }^{5}$ :

$$
\begin{aligned}
\text { Lik }_{i}= & \left.\operatorname{Pr}\left(\text { Cost }_{i}=y_{i}{\text { \& } \left.\text { Condemn }_{i}=0 \text { or } 1\right)} \text { Condemn }_{i}=1\right)\right]^{\text {Oondemn }_{i}} \\
= & {\left[\operatorname { P r } \left(y_{i}=y_{1 i}, \text { Condemn }_{i}\right.\right.} \\
& {\left[\operatorname{Pr}\left(y_{i}=y_{2 i}, \text { Condemn }_{i}=0\right)\right]^{1-\text { Condemn }_{i}} } \\
= & {\left[\operatorname{Pr}\left(y_{i}=y_{1 i}\right) \cdot \operatorname{Pr}\left(\text { Condemn }_{i}=1 \mid y_{i}=y_{1 i}\right)\right]^{\text {Condemn }_{i}} . } \\
& {\left[\operatorname{Pr}\left(y_{i}=y_{2 i}\right) \cdot \operatorname{Pr}\left(\text { Condemn }_{i}=0 \mid y_{i}=y_{2 i}\right)\right]^{1-\text { Condemn }_{i}} }
\end{aligned}
$$

where

$$
\begin{gathered}
\operatorname{Pr}\left(y_{i}=y_{j i}\right)=\operatorname{Pr}\left(y_{i}=x_{j i}^{\prime} \beta_{j}+\varepsilon_{j i}\right)=\frac{1}{\sigma_{j}} \phi\left(\frac{y_{i}-x_{j i}^{\prime} \beta_{j}}{\sigma_{j}}\right) \\
\operatorname{Pr}\left(\text { Condemn }_{i}=1 \mid y_{i}=y_{j i}\right)=\operatorname{Pr}\left(u_{i} \mid \varepsilon_{j i}=\varepsilon_{j 0}>-\gamma^{\prime} Z_{i}\right) \\
=\Phi\left(\frac{\gamma^{\prime} Z_{i}+\rho_{j u}\left(y_{i}-x_{j i}^{\prime} \beta_{j}\right) / \sigma_{j}}{\sqrt{1-\rho_{j u}^{2}}}\right) \\
\operatorname{Pr}\left(\text { Condemn }_{i}=0 \mid y_{i}=y_{j i}\right)=\operatorname{Pr}\left(u_{i} \mid \varepsilon_{j i}=\varepsilon_{j 0} \leq-\gamma^{\prime} Z_{i}\right) \\
=1-\Phi\left(\frac{\gamma^{\prime} Z_{i}+\rho_{j u}\left(y_{i}-x_{j i}^{\prime} \beta_{j}\right) / \sigma_{j}}{\sqrt{1-\rho_{j u}^{2}}}\right)
\end{gathered}
$$

where $\phi($ ) and $\Phi($ ) represent the standard normal density function; and $j=1,2$ represents condemnation and negotiation regime, respectively.

\section{ESTIMATION AND RESULTS}

\footnotetext{
${ }^{5}$ See Lokshin and Sajaia (2004) and Maddala (1983) for more detailed estimation procedures.
} 
Table 2 shows all model parameters, as estimated using STATA's least-squares command and its "Movestay" module (Lokshin and Sajaia, 2004). Table 2's first column shows ordinary least squares (OLS) regression parameter estimates for the natural $\log$ of acquisition cost as the dependent variable, using a single-equation (single regime) to represent all 1,710 parcels at once, without any switching. The second, third and fourth columns present the parameter estimates for the binary acquisition-type equation (condemnation or not) and the two acquisition cost equations (for parcels that were acquired via condemnation or negotiation), respectively. The OLS parameter estimates are similar to those estimated for acquisition by negotiation in large part because negotiation is far more common than condemnation in the data set $(1,457$ or 85 percent of the 1,710 acquired properties). Nevertheless, the likelihood-ratio test for joint independence indicates a very statistically significant (at the 0.01 level) correlation between acquisition type and final acquisition costs, underscoring the value of a two-regime model for these data. Moreover, all of the switching regression model's retained explanatory variables are statistically significant at the 0.10 level.

Table 3 presents estimates of different explanatory variables' elasticities (for continuous variables) and marginal effects (for indicators) on acquisition costs per square foot, all by different land use types (agricultural, residential, commercial, vacant, and all other uses). Elasticities of continuous variables quantify the percentage change in estimated acquisition cost per square foot (of taken land) associated with a one-percent change in the covariate $X_{k}$, while the marginal effects of indicator variables characterize the (estimated) change in expected cost per square foot (of taken land) after changing the binary attribute $X_{k}$ from 0 to 1 . The marginal effects of these variables on the probability of condemnation were also calculated, to characterize their practical significance in predicting acquisition type. The elasticities and marginal effects can be written as follows:

$$
\begin{aligned}
& \text { Elasticity (Cost per sq } \mathrm{ft})=\left.\frac{\partial \log (\text { Cost per sq ft })}{\partial \log \left(x_{k}\right)}\right|_{x_{*}} \\
& \text { Marginal Effect (Cost per sq ft) } \\
& \quad=\left[\text { Cost (per sq ft) } \mid x_{k}=1, x_{*}\right]-\left[\text { Cost (per sq ft) } \mid x_{k}=0, x_{*}\right] \\
& \text { Marginal Effect (Prob) } \\
& \quad=\operatorname{Pr}\left(\text { Condemn. }=1 \mid x_{k}=1, x_{*}\right)-\operatorname{Pr}\left(\text { Condemn. }=1 \mid x_{k}=0, x_{*}\right)
\end{aligned}
$$

where $x_{*}$ represents the base case's set of attributes. This base case acquisition holds all attributes at their sample mean value (for continous variables) or mode value (for indicators): 796 persons per square mile of population density, 49,400 square feet $(1.13$ acres $)$ of taken land area, Texas' northern region location ( $66 \%$ of the sample), partial taking type (90.1\% of the sample), 48,900 square feet (1.12 acres) of remainder area ${ }^{6}$, individual-ownership-type (51.3\% of the sample), and a 2009 acquisition year ( $45.4 \%$ of the sample).

Estimates of these elasticities and marginal effects typically rely on simulation of parameter values, rather than simple insertion of mean parameter estimates into equations 6 to 8 , which can be misleading. All model parameters were randomly generated 1,000 times assuming a multivariate normal distribution (the maximum-likelihood estimator's asymptotic distribution), and then the probability of condemnation and acquisition costs (for both regimes) were computed for each parcel with each set of simulated parameter values. Biases due to log-transformation of acquisition costs were essentially removed by using the following log-normal expression:

$$
\mathrm{E}(Y)=\mathrm{E}\left(\mathrm{e}^{x^{\prime} \beta+\varepsilon}\right)=\mathrm{e}^{x^{\prime} \beta} \mathrm{E}\left(\mathrm{e}^{\varepsilon}\right)=\mathrm{e}^{x^{\prime} \beta} \mathrm{e}^{\sigma^{2} / 2}
$$

\footnotetext{
${ }^{6}$ This remainder area was obtained by back-transforming the average of the sample's log-remainder values to avoid its right-skew.
} 
The next two sections present the estimation results (including the statistical and practical significance of different explanatory variables) and acquisition cost differences between the two regimes (condemnation and negotiation).

\section{Acquisition Type and Cost Equations Results}

As shown in columns 2 through 4 of Table 2, the time trend variable (tracking the year of acquisition) has a positive effect on land values, suggesting an increase of $\$ 1.15$ to $\$ 1.53$ per square foot per year. The population density variable has a positive effect on both condemnation likelihood and final acquisition costs (a one percent increase in population density [persons per square mile] appeared to trigger a $0.54 \%$ to $0.70 \%$ increase in costs per square foot [of taken land]); this is as expected, since there are higher property values, generally more educated (and higher income) property owners ${ }^{7}$, and presumably better access to legal representation in more densely populated urban counties. As one can see from Table 3, the amount of land taken also has a practically significant impact on acquisition costs. A one percent increase in taken land is estimated to trigger a $0.28 \%$ to $0.37 \%$ decrease in cost per square foot (of taken land), presumably thanks to economies-of-scale effects. Specifically, costs per square foot decline most quickly for agricultural land (with an elasticity of -0.38 to $-0.48 \%$ ), and most slowly for commercial land (with an elasticity of $-0.23 \%)$, among all land uses.

The location indicators for Texas northern, eastern and southern regions are all statistically significant in the OLS (price-paid) and condemnation models, with eastern parcels most often condemned (everything else constant), followed by parcels in southern and then northern locations, all relative to a western location (where condemnation is least likely, ceteris paribus). An eastern location was estimated to raise the condemnation probability by $17 \%$ (from $14 \%$ to $31 \%$ ) for properties in non-commercial use and $21 \%$ (from $26 \%$ to $47 \%$ ) in commercial use, relative to the base, northern location, everything else constant. These eastern, southern, and northern regions include the state's most populous regions, of course: the Houston, Austin/San Antonio, and DallasFt. Worth metro areas contain roughly 6.0, 2.6 and 6.4 million persons, respectively. Interestingly, the results also suggest that eastern Texas parcels do not enjoy statistically or practically significantly higher acquisition costs (via negotiation or condemnations). Table 3 shows northern locations also tend to result in higher acquisition costs (relative to other locations) if a parcel is acquired by negotiation, with the increased amount varing from $\$ 0.17$ to $\$ 1.23$ per square foot for different land uses, everything else constant, reflecting regional differences in land valuation and wealth (in addition to those explained by the model's county-level population density variable). However, such valuation differences are not apparent across the four regions (in any statistically significant way) when such parcels go to condemnation, perhaps because formal, legal proceedings ensure smaller price variation among regions, everything else constant.

As expected, various land uses trigger cost-equation differences. Interestingly, the coefficient estimates are very similar across the two regimes except for cases of commercial use, where the condemnation cost bump is much higher, on average (versus acquisition of commercial porperties via negotiation). Commercial use is also the only ROWIS parcel-use indicator that is statistically significant in predicting the probability of condemnation. Parcels in commercial use averaged a $12 \%$ higher condemnation probability than non-commercial use (i.e., $26 \%$ vs. 14\%). Their costs were estimated to be $\$ 6.55 / \mathrm{sq} \mathrm{ft}$ if acquired via negotiation and $\$ 19.92 / \mathrm{sq} \mathrm{ft}$ if condemned above the average of all land uses (see Table 3), everything else constant (including taken area, year of acquisition, county density value, and region indicator). Transportation planners, appraisers, and R/W staff should pay special attention to these properties in the acquisition process (and perhaps the alignment design process).

\footnotetext{
${ }^{7}$ Using Census 2000 data, the correlation between population density and the share of those 25 years and older with a college degree is 0.42 in Texas ( 254 counties). The correlation is 0.36 between population density and per capita income.
} 
Approximately 90 percent of the sample's parcels involve partial takings, and this indicator has a positive effect on condemnation likelihood and both regimes' acquisition cost estimates, consistent with the expectation that partial takings generally entail damages of some sort (e.g., removal of driveways, parking spaces, buildings, or other improvements). Smaller remainders also increase the chance of condemnation and higher acquisition costs, but without practically significant effects (e.g., a one percent change in remainder area triggered only a $0.12 \%$ change in costs per square foot [see Table 3]).

Partial takings with a remainder area of 48,900 square feet (with its natural log equal to the average of the sampled log-remainder values) were estimated to increase the condemnation probability by approximately $5 \%$ (i.e., from $20 \%$ to $25 \%$ ), relative to whole takings. Patial takings in commerical use increased average acquisition costs by $\$ 3.24 / \mathrm{sq} \mathrm{ft}$ if negotiated and $\$ 8.68 \mathrm{sq} / \mathrm{ft}$ if condemned, everything else constant. Such jumps can easily mean hundreds of thousands of dollars more for a single property's acquisition. Interestingly, the costs of non-commercial properties did not experience such drastic increase when partial takings occurred. Instead, they even averaged $\$ 1.00 / \mathrm{sq} \mathrm{ft}$ less if acquired via negotiation but still $\$ 1.41 / \mathrm{sq} \mathrm{ft}$ more if condemned, relative to whole takings. Perhaps the acquired portions of these non-commercial properties were less valuable than their remainders, or the damages entailed from such partial takings were under-estimated in initial appraisals, with more details leading to higher compensation examined during condemnation proceedings.

The individual- and corporation-ownership-type variables also appear to increase the condemnation probability by $7 \%$ (from $13 \%$ to $20 \%$ ) and $11 \%$ (from $13 \%$ to $24 \%$ ), respectively, relative to other ownership types. However, they do not appear to directly affect acquisition costs. It may be that corporations have easier (including in-house) access to legal support in eminent domain cases, but the presence of a legal process levels the playing field, in terms of condemnation awards. Nevertheless, these ownership types can still positively influence acquisition costs (indirectly), since condemnation tends to result in higher model-estimated costs, as discussed in the next section.

The correlation coefficient of error terms between the acquisition-type and negotiation-cost equations is negative and practically (and statistically) significant,yet not statistically significant for the condemnation likelihood-and-cost connection. A priori, one might have expected that unobserved factors leading to condemnation proceedings also lead to higher acquisition costs (e.g., corner parcels with better access may carry a higher risk of condemnation as well as higher value and thus acquisition cost), but that appears to not be the case here. It may simply be that the parcels more likely to be condemned are also less valuable, ceteris paribus, due to unusual features that render the parcels problematic and therefore more contentious (e.g., poor soils, odd shapes and topography, poor visibility). However, these less-valuable parcels may or may not end up with lower payments if they go to condemnation (e.g., the owners are really attached to their properties and do not want to give them up), since more compensable details can emerge through the process of condemnation (Caldas, et al., 2011). The following section further compares differences in acquisition costs between the two regimes.

\section{Comparing Acquisition Cost Differences}

While the acquisition cost equation for the condemnation regime enjoys a higher constant than the negotiation regime, the estimated coefficients for several explanatory variables and the land-area interacted terms (e.g., time trend, population density and partial taking indicator) are slightly higher in the negotiation-cost regime, so some negotiated parcels may end with higher acquisition cost estimates. It may be that TxDOT made relatively high initial offers therebyavoiding condemnation proceedings and expediting the $\mathrm{R} / \mathrm{W}$ acquisition process.

Table 4 compares the estimated costs and their standard deviation across the two acquistion types (condemnation and negotiation). According to the simulation results, $57.9 \%$ of sample properties have higher predicted acquisition costs if they were to go to condemnation, with an 
average increase of $\$ 14.7$ in acquisition cost per square foot, which is equivalent to an average percentage increase of $77.8 \%$ in total cost. This striking represents almost a doubling in cost. The results also show how acquisition costs in the condemnation regime can exhibit substantial variance (averaging of $51.1 \%$ greater standard deviation, as compared to values predicted under the negotiation regime). Such findings underscore the notion that condemned parcels may experience higher variation in price (ceteris paribus), so their costs are more difficult to predict accurately.

Table 4 also provides point estimates for comparisons (as obtained using mean parameter estimates). These are close to the simulated estimates except for condemnation costs, where fewer data points exist and outcome uncertainties are higher (as discussed earlier). Specifically, while both estimation methods produce similar shares of parcels generating higher condemnation cost (57.9\% when simulated and 59.3\% when using point estimates), the latter tends to predict a much smaller scale of cost increase (77.8\% when simulated and $21.4 \%$ when using point estimates) if a parcel cannot be acquired via negotiation. Essentially, the marginal effects of explanatory variables on acquisition costs of condemned parcels involve more uncertainties and are highly variable, which can be a significant source of estimation errors. Such uncertainty is better captured by taking into account the variance and covariance of the parameters (i.e., simulating from their [approximate] distribution). Data analysts should be wary of biases that can arise in interpretating the model results using simple point estimates.

Table 5 shows an applied example of prediction for a 9-parcel corridor in Brazoria County (Houston), highlighting the value of simulation to capture all modeling uncertainties (especially those in the condemnation regime, where simulation generates quite different estimates from use of point estimates). Such predictions could assist R/W staff in identifying potential condemnation settlements and provide possible cost outcomes (recognizing the impact of condmnation), which may help in establishing the basis of cost estimation in $\mathrm{R} / \mathrm{W}$ acquisition.

\section{EXTENSIONS TO THIS WORK}

This work can be furthered through various data improvements. Adding more attributes of the acquiring parcels and their remainders (e.g., size and type of any improvements taken, presence and magnitude of damages, shape and use of remainders, and site accessibility) into the model would allow for more thorough analysis. Also, data from non-Texas regions with more generic variables may provide additional insight on effects of regional demographics and other attributes.

Another extension is to allow for more than two acquisition types. For example, one can classify ROWIS' observations into four regimes: Negotiation-Deed $(j=0)$, NegotiationAdmininstrative Settlement $(j=1)$, Condemnation-Special Commissioner's Award $(j=2)$, and Condemnation-Protracted Process $(j=3)$. The selection mechanism could be modelled using a Multinomial Probit Model (MNP), with bivarate normal distributions between the error terms of each selection equation and that regime's corresponding cost equation, as discussed in GarcíaPérez and Rebollo-Sanz (2005). Essentially, the selection process could be described as follows:

$$
\begin{aligned}
& I_{n j}=\gamma_{n j}{ }^{\prime} Z_{n j}+u_{n j} \\
& Y_{n}=Y_{n k}, \text { if } I_{n k}=\max \left\{I_{n j}\right\}, j=0,1,2,3 .
\end{aligned}
$$

Here, Equation 10 is the selection equation (or utility expression), where $I_{n j}$ is a latent variable that reflects a parcel's tendency to be acquired under regime-type $j$. The $Z_{n j}$ represent vectors of parcel $i$ 's characteristics affecting the selection process, and $u_{n j}$ are unobserved components of the associated selection equations. Finally, $Y_{n}$ is the acquisition cost observed under the "winning" regime (i.e., that with the highest $I_{n k}$ values). 
Since only utility differences are relevant in the selection process, one can take the Negotiation-Deed regime $(j=0)$ as a reference, reducing the selection process to three equations:

$$
I_{n j}^{*}=I_{n j}-I_{n 0}=\gamma_{n j}^{*} Z_{n j}+u_{n j}^{*}, j=0,1,2,3 .
$$

where $\gamma_{n j}^{*}=\gamma_{n j}-\gamma_{n 0}$ and $u_{n j}^{*}=u_{n j}-u_{n 0}$.

Thus, the distribution of the differences in selection equation error terms is a trivarate normal, with zero means and the following variance-covariance matrix:

$$
\Omega^{*}=\left[\begin{array}{lll}
\sigma_{11}^{*} & \sigma_{12}^{*} & \sigma_{13}^{*} \\
\sigma_{12}^{*} & \sigma_{22}^{*} & \sigma_{23}^{*} \\
\sigma_{13}^{*} & \sigma_{23}^{*} & \sigma_{33}^{*}
\end{array}\right]
$$

The covariance between the selection equation's error term and its corresponding cost equation is $\sigma_{u_{j} \varepsilon_{j}}$. The $\sigma$ are not defined for error terms across cost equations, since the acquisition $\operatorname{cost}\left(Y_{n}\right)$ can be observed for only one regime at each property. This extended-switching regression model requires more demanding estimation techniques. García-Pérez and Rebollo-Sanz (2005) have discussed a full-information maximum likelihood (FIML) method to estimate such a model across three regimes (to predict wages in three employment contexts). And Preminger et al. (2007) developed an expectation maximization (EM) algorithm to estimate the model with more categories (to forecast exchange rates under different states of the economy). Other approaches are maximum simulated likelihood estimation (Train, 2003) and Bayesian techniques. Allowance for more acquistion-type categories in the case of $\mathrm{R} / \mathrm{W}$ may illuminate other cost differences that emerge, at different stages of the $\mathrm{R} / \mathrm{W}$ acquistion process.

\section{CONCLUSIONS}

This paper offers a series of meaningful insights for those involved in the R/W acquisiton cost process by highlighting the significant cost disparities that emerge between condemnation and negotiaton regimes. The work developed two acquisition-cost equations with endogenous switching, reflecting the reality that $\mathrm{R} / \mathrm{W}$ staff and apparisers do not know which properties will require condemnation proceedings.

Model results illuminate the effect of key parcel attributes in predicting R/W acquisiton outcomes, and suggest that $\mathrm{R} / \mathrm{W}$ appraisers and staff should pay special attention to parcels in commercial use involving a partial taking with a relatively small remainder and located in more urbanized areas. Comparison of the cost estimates between the two regimes (condemnation vs. negotiation) suggest that condemned parcels average $78 \%$ higher acquisition costs per acquired property and $51 \%$ greater price variation than their negotiated counterparts, at least when relying on recent Texas acquisition data.

The ROWIS data set only offers - and thus the model only predicts - costs paid to the property owners. The model does not anticipate other, less tangible costs that can result from condemnation proceedings, such as delays in construction, a less positive public perception of agencies and their ED projects, and more staff effort and time (including attorneys' fees). As suggested in Table 6's least-square regression results ${ }^{8}$ for acquisition duration (from DOT's initial-

\footnotetext{
${ }^{8}$ A switching regression was also performed for acquisition durations under the two regimes, but its parameters were not robustly identified due, apparently, to greater variation in acquisition durations and the data set being limited to imperfect control variables. As Gibson et al. (2006) alludes, duration may also be more challenging to predict than acquisition cost due to variations introduced
} 
offer date to possession date), condemnation proceeding can significantly lengthen the acquistion process, adding approximately 7 to 8 months for each parcel, on average (as compared to the sample's base case conditions). In future work, such delays may be evaluted as additional "costs" of acquisition. Also, as discussed earlier, adding data records and more attributes of the acquired parcels and their remainders would be helpful. Another extension to this work is to incorporate more categories of $\mathrm{R} / \mathrm{W}$ acquisition into the model, illuminating key points entailing significant cost changes at different stages of $\mathrm{R} / \mathrm{W}$ acquistion. Regardless of the methods used, the costs and time involved are real. If projects are to meet budget targets and agencies are to address project delays, more sophistication is needed in this practice area.

\section{ACKNOWLEDGEMENTS}

The authors wish to thank the Texas Department of Transportation for supporting the data collection and research work for this paper under research project No. 0-6630, Elizabeth Kincaid for useful discussions regarding $\mathrm{R} / \mathrm{W}$ acquisition process and data used for this work.

\section{REFERENCES}

Abelson, P.W. (1997) House and Land Prices in Sydney from 1931 to 1989. Urban Studies 34(9): 1381.

Abdelwahab, W. M. and Sargious, M. A. (1991) A Simultaneous Decision-Making Approach to Model the Demand for Freight Transportation. Canadian Journal of Civil Engineering 18 (3): $515-$ 520 .

Anderson, S. D., Molenaar, K. R., and Schexnayder, C. (2009) Procedures Guide for Right-of-Way Cost Estimation and Cost Management. National Cooperative Highway Research Program (NCHRP) Report No. 625. Transportation Research Board. URL: http://onlinepubs.trb.org/onlinepubs/nchrp/nchrp_rpt_625-2.pdf (Accessed on 15 July 2011).

Bhat, C. R. and Koppelman, F. S. (1993) An Endogenous Switching Simultaneous Equation System of Employment, Income, and Car Ownership. Transportation Research Part A: Policy and Practice 27(6): 447-459.

Bina, M. and Kockelman, K. (2009) Kitamura, R. and Yoshii, T. (Eds.) Location Choice Vis-A-Vis Transportation: the Case of Recent Home Buyers. The Expanding Sphere of Travel Behavior Research: 597-619.

Buffington, J. L., Chui, M. K., Memmott, J. L., and Saad, F. (1995) Characteristics of Remainders of Partial Takings Significantly Affecting Right-of-Way Costs. Research Report No. FHWA/TX95/1390-2F. Texas Department of Transportation. URL: http://tti.tamu.edu/documents/1390-2F.pdf (Accessed on 15 July 2011).

Bureau of Labor Statistics (BLS) (2011) Consumer Price Index - All Urban Consumers. U.S. Department of Labor. URL: http://www.bls.gov/cpi/home.htm (Accessed on 3 April 2011).

Caldas, C. H., Bhat, C. R., and Kockelman, K. M. et al. (2011) Technical Memorandum: TxDOT Research Project 0-6630: Condemnation in Transportation Projects: Causes and Solutions. The University of Texas at Austin.

by title curative issues (e.g., deceased owners, multiple ownership, and bankruptcy), legal activities (e.g., coordination of attorneys, witnesses, meeting places, judges, court reporters, and R/W personnel), and other resource- or manpower-related delays. 
Caldas, C. H., Zhang, Z., and Kockelman, K. M. et al. (2006) Synthesis of Best Practices in Rightof-Way Valuations and Negotiations. Research Report No. FHWA/TX-07/0-5379-1. The University of Texas at Austin. URL:

http://www.utexas.edu/research/ctr/pdf_reports/0_5379_P1.pdf (Accessed on 3 April 2011).

FHWA (2011a) Annual Right-of-Way Statistics. URL:

http://www.fhwa.dot.gov/realestate/rowstats/ (Accessed on 19 April 2011).

FHWA (2011b) Evaluation of State Condmenation Process. URL:

http://www.fhwa.dot.gov/realestate/cndmst.htm (Accessed on 15 July 2011).

FHWA (2010) Uniform Relocation Assistance and Real Property Acquisition Policies Act of 1970 as amended. URL: http://www.fhwa.dot.gov/realestate/act.htm (Accessed on 28 June 2011).

FHWA (2009) Real Estate Acquisition Guide For Local Public Agencies. URL:

http://www.fhwa.dot.gov/realestate/lpaguide/reag.pdf (Accessed on 5 July 2011).

FHWA (2007) Policy and Guidance Supercompensation Payments Incurred for Acquisition of Real Property on Projects Eligible for Federal Funding. URL:

http://www.fhwa.dot.gov/realestate/supercompguid.htm (Accessed on 5 July 2011).

FHWA (2002) Acquiring Real Property for Federal and Federal-Aid Programs and Projects. FHWA Publication No. FHWA-PD-95-005. U.S. Department of Transportation.

Gallego, A. V. (1996) Interrelation of Land Use and Traffic Demand in the Estimation of the Value of Property Access Rights. MSCE thesis. The University of Texas at Austin.

García Pérez, J. I. and Y. Rebollo Sanz (2005) Wage Changes through Job Mobility in Europe: A Multinomial Endogenous Switching Approach. Labour Economics 12(4): 531-555.

Gelfand, A. E., Ecker, M. D. et al. (2004) The dynamics of location in home price. The Journal of Real Estate Finance and Economics 29(2): 149-166.

Georgia Department of Transportation (GDOT) (2007) Planning Level Cost Estimation Study. URL:http://www.dot.state.ga.us/informationcenter/programs/studies/Pages/CostEstimationStudy.as px (Accessed on 17 July 2011).

Gibson, Jr., G. E., O’Connor J. T., Chang, G. R., Hedemann, S. M., and Chong, W. K. (2006) Durations for Acquiring Roadway Right-of-Way and Assorted Expediting Strategies. Research Report No. FHWA/TX-06/0-4617-1. The University of Texas at Austin. URL: $\mathrm{http}: / /$ www.utexas.edu/research/ctr/pdf_reports/0_4617_1.pdf (Accessed on 30 June 2011).

Hakimi, S., Kockelman,K. M. (2005) Right-of-Way Acquisition and Property Condemnation: A Comparison of U.S. State Laws. Journal of the Transportation Research Forum 44(3): 45-58.

Heiner, J. D. and Kockelman, K. M. (2005) The Costs of Right of Way Acquisition: Methods and Models for Estimation. Journal of Transportation Engineering 131(3): 193-204.

Iacono, M. J. and Levinson, D. M. (2009) The Economic Impact of Upgrading Roads. Minnesota Department of Transportation Research Report No. Mn/DOT 2009-16. University of Minnesota. URL: http://www.cts.umn.edu/Publications/ResearchReports/reportdetail.html?id=1804 (Accessed on 20 July 2011).

Kades, E. (2008) A Positive Theory of Eminent Domain. 3rd Annual Conference on Empirical Legal Studies Papers; William \& Mary Law School Research Paper No. 08-08. URL: http://ssrn.com/abstract $=1086789$ (Accessed on 7 Dec 2010).

Kockelman, K. M., Caldas, C. H. Zhang, Z., Gao, L., and Escatel, R. (2006) Estimating the Cost of Right-of-Way Acquisitions Along Texas Corridors. Research Report No. FHWA/TX-07/5-4079- 
01-1. The University of Texas at Austin. URL:

http://www.utexas.edu/research/ctr/pdf_reports/5_4079_01_1.pdf (Accessed on 7 Dec 2010).

Kockelman, K. M., Machemehl R. et al. (2003) Frontage Roads: Assessment of Legal Issues, Design Decisions, Costs, Operations, and Land-Development Differences. Journal of transportation engineering 129(3): 242-252.

Krugler, P. E., Chang-Albitres, C. M. et al. (2010) Development of Decision-making Support Tools for Early Right-of-Way Acquisitions. Research Report No. FHWA/TX-10/0-5534-2. The Texas A\&M University System. URL: http://tti.tamu.edu/documents/0-5534-2.pdf (Accessed on 3 April 2011).

Lee, L. F. (1978) Unionism and Wage Rates: A Simultaneous Equations Model with Qualitative and Limited Dependent Variables. International Economic Review 19(2): 415-433.

Le, T. (2009) Improving Right-of-Way Acquisition in Highway Projects through Scope Definition and Management of Inherent Factors. Ph.D. dissertation. The University of Texas at Austin.

Lokshin, M. and Sajaia, Z. (2004) Maximum-likelihood Estimation of Endogenous Switching Regression Models. The Stata Journal 4 (3): 282-289.

Maddala, G. S. (1986) Griliches, Z. and Intriligator M. D. (eds.) Disequilibrium, Self-Selection, and Switching Models. Handbook of Econometrics 3: 1663-1688.

Maddala, G. S. (1983) Limited-Dependent and Qualitative Variables in Econometrics. Cambridge University Press. Cambridge.

Meurs,H. (1993) A Panel Data Switching Regression Model of Mobility and Car Ownership. Transportation Research Part A 27(6): 461-467.

Peiser, R. B. (1987) The determinants of nonresidential urban land values. Journal of Urban Economics 22(3): 340-360.

Preminger, A., Ben-zion, U., and Wettstein, D. (2007) The Extended Switching Regression Model: Allowing for Multiple Latent State Variables. Journal of Forecasting 26(7): 457-473.

Texas Department of Transportation (TxDOT) (2009) Regional Services Centers. URL: http://www.dot.state.tx.us/local_information/regions/default.htm (Accessed on 9 May 2011).

Train, K. (2003) Discrete Choice Methods with Simulation. Cambridge Univ Press. Cambridge.

Trost, R. (1977) Demand for Housing: A Model Based on Inter-related Choices Between Owning and Renting. Ph. D. dissertation. University of Florida.

Virginia Department of Transportation (VDOT) (2005) Capital Cost Estimate and Methodology

Technical Report. URL:

http://www.virginiadot.org/projects/resources/TCP_Capital_Costs_Tech_Rpt_031005.pdf

(Accessed on 15 July 2011).

Westerfield, H. (1993) A Model for Estimating the Value of Property Access Rights. MSCE thesis. The University of Texas at Austin.

Wilhelmsson, M. (2000) The Impact of Traffic Noise on the Values of Single-family Houses. Journal of Environmental Planning and Management 43(6): 799-815. 


\section{LIST OF TABLES}

Table 1 Summary Statistics of ROWIS Data Sample for Parcels Acquired by Negotiation and Condemnation between 2008 and 2011 in Texas $\left(\mathrm{n}_{\mathrm{obs}}=1,710\right)$ 15

Table 2 Regression Results of R/W Acquisition Type and Final Acquisition Cost ........................16

Table 3 Elasticities and Marginal Effects of Various Attributes on Acquisition Costs $(\$ / \mathrm{sq} \mathrm{ft})$ :

Negotiation vs. Condemnation

Table 4 R/W Acquisition Cost Estimates Comparison: Negotiation vs. Condemnation

Table 5 Application of Switching Regression Model Prediction for 9-parcel Corridor in Brazoria

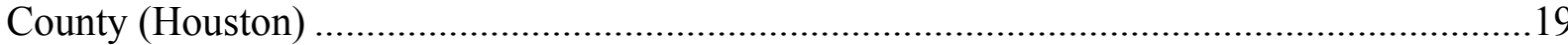

Table 6 OLS Regression Results for Duration (Time till Acquisition) .........................................20 
Table 1 Summary Statistics of ROWIS Data Sample for Parcels Acquired by Negotiation and Condemnation between 2008 and 2011 in Texas $\left(n_{\text {obs }}=1,710\right)$

\begin{tabular}{|l|l|c|c|}
\hline Variables & \multicolumn{1}{|c|}{ Description } & Average & Std. Dev \\
\hline Condemnation & Parcel possession type is condemnation & 0.15 & 0.36 \\
\hline TotalCost & Total acquisition cost (\$ 2011 Jan) & $2.36 \mathrm{e}+05$ & $7.91 \mathrm{e}+05$ \\
\hline LnTotalCost & Natural log of total cost & 10.58 & 1.98 \\
\hline TakenSF & Land area of part acquired (sf) & $1.44 \mathrm{e}+04$ & $1.59 \mathrm{e}+05$ \\
\hline RemainderSF & Land area of remainder parcel (sf) & $4.74 \mathrm{e}+08$ \\
\hline TimeTrend & $\begin{array}{l}\text { Trend variable for year of acquisition(1=2008, } \\
\text { 2=2009,...4=2011) }\end{array}$ & 2.31 & 0.69 \\
\hline North & Indicator for northern region of Texas & 0.66 & 0.47 \\
\hline South & Indicator for southern region of Texas & 0.15 & 0.36 \\
\hline East & Indicator for eastern region of Texas & 0.14 & 0.35 \\
\hline West & Indicator for western region of Texas & 0.04 & 0.20 \\
\hline PopDensity & $\begin{array}{l}\text { Population density (at county level) per } \\
\text { square mile (U.S. Census, 2010) }\end{array}$ & 795.7 & 852.8 \\
\hline Agriculture & Indicator variable for agricultural land use & 0.09 & 0.29 \\
\hline Residential & Indicator variable for residential land use & 0.26 & 0.44 \\
\hline Commercial & $\begin{array}{l}\text { Indicator variable for commercial, retail and } \\
\text { service land uses }\end{array}$ & 0.35 & 0.48 \\
\hline OtherUse & $\begin{array}{l}\text { Indicator variable for other land use (e.g., } \\
\text { ecclesiastical, industry, education, multi-use, } \\
\text { and special use) }\end{array}$ & 0.06 & 0.24 \\
\hline Vacant & Indicator variable for vacant land & 0.24 & 0.42 \\
\hline PartialTaking & Indicator variable for parcel with a remainder & 0.90 & 0.30 \\
\hline Ratio & Fraction of taken area to total area & 0.20 & 0.31 \\
\hline Individual & $\begin{array}{l}\text { Indicator variable for individual ownership } \\
\text { type }\end{array}$ & 0.51 & 0.50 \\
\hline Corporation & $\begin{array}{l}\text { Indicator variable for corporation and } \\
\text { partnership ownership type }\end{array}$ & 0.38 & 0.49 \\
\hline OtherOwnership & $\begin{array}{l}\text { Indicator variable for other ownership types } \\
\text { (e.g., federal agency, state agency, and } \\
\text { municipality) }\end{array}$ & 0.10 & 0.30 \\
\hline
\end{tabular}

Note:The map of the four Texas regions can be found at TXDOT Regional Services Center (2009). 
Table 2 Regression Results of R/W Acquisition Type and Final Acquisition Cost

\begin{tabular}{|c|c|c|c|c|}
\hline \multirow{3}{*}{$\begin{array}{l}\text { Model } \\
\text { Variables }\end{array}$} & \multirow{2}{*}{$\begin{array}{l}(1) \\
\text { OLS }\end{array}$} & \multirow{2}{*}{\multicolumn{3}{|c|}{ Endogenous Switching Regression }} \\
\hline & & & & \\
\hline & Acquisition Cost & $\begin{array}{c}\text { Condemnation } \\
\text { Model } \\
(1 \text { or } 0)\end{array}$ & $\begin{array}{c}\text { Regime 1 } \\
\text { (Condemn. }=1 \text { ) } \\
\text { Acquisition } \\
\text { Cost for } \\
\text { Condemnation } \\
\text { Parcel } \\
\end{array}$ & $\begin{array}{c}\text { Regime } 2 \\
\text { (Condemn. }=0 \text { ) } \\
\text { Acquisition Cost } \\
\text { for Negotiation } \\
\text { Parcel }\end{array}$ \\
\hline (Constant) & $4.139(23.24)$ & $-2.426(-9.07)$ & $4.452(3.56)$ & $4.099(20.19)$ \\
\hline \multicolumn{5}{|l|}{ Taken Area } \\
\hline $\ln ($ TakenSF) & $0.385(19.27)$ & - & $0.363(6.85)$ & $0.387(17.36)$ \\
\hline $\ln ($ TakenSF $) \times$ TimeTrend & $0.057(6.86)$ & - & $0.053(2.42)$ & $0.055(5.59)$ \\
\hline $\ln ($ TakenSF $) \times$ PopDensity & 8.63E-05 (19.34) & 3.33E-05 (6.15) & $6.22 \mathrm{E}-05(4.58)$ & 8.08E-05 (14.75) \\
\hline $\ln ($ TakenSF $) \times$ North & $0.057(3.26)$ & $0.053(2.65)$ & - & $0.062(3.06)$ \\
\hline $\ln ($ TakenSF $) \times$ East & - & $0.108(5.12)$ & - & - \\
\hline $\ln ($ TakenSF $) \times$ South & - & $0.073(3.47)$ & - & - \\
\hline $\ln ($ TakenSF $) \times$ Residential & $0.079(6.66)$ & - & $0.077(2.31)$ & $0.078(5.73)$ \\
\hline $\ln ($ TakenSF $) \times$ Commercial & $0.173(8.60)$ & $0.038(3.64)$ & $0.268(6.73)$ & $0.139(5.77)$ \\
\hline $\ln ($ TakenSF $) \times$ Vacant & $0.101(9.25)$ & - & $0.108(3.40)$ & $0.100(7.99)$ \\
\hline $\ln ($ TakenSF $) \times$ OtherUse & $0.136(8.88)$ & - & $0.111(2.02)$ & $0.139(8.12)$ \\
\hline \multicolumn{5}{|l|}{ Remainder } \\
\hline PartialTaking & $1.611(8.25)$ & $1.107(3.95)$ & $1.389(2.67)$ & $1.474(5.87)$ \\
\hline $\ln ($ RemainderSF $)$ & - & $-0.085(-4.19)$ & - & - \\
\hline $\ln ($ RemainderSF $) \times$ TimeTrend & $-0.041(-6.99)$ & - & $-0.045(-2.60)$ & $-0.036(-5.05)$ \\
\hline $\ln ($ RemainderSF $) \times$ North & $-0.074(-5.39)$ & - & - & $-0.080(-5.11)$ \\
\hline $\ln ($ RemainderSF $) \times$ East & $-0.051(-6.27)$ & - & - & $-0.065(-6.88)$ \\
\hline $\ln ($ RemainderSF $) \times$ Commercial & $0.033(2.44)$ & - & - & $0.044(2.70)$ \\
\hline \multicolumn{5}{|l|}{ Ownership Type } \\
\hline Individual & & $0.302(2.02)$ & & \\
\hline Corporation & & $0.430(2.21)$ & & \\
\hline Sigma & & & $1.138(14.71)$ & $1.207(31.99)$ \\
\hline Corr. Coef. & & & $0.068(0.15)$ & $-0.570(-2.76)$ \\
\hline Dependent Variable & \\
\hline Number of Obs. & \multirow{2}{*}{\multicolumn{4}{|c|}{1710 ( 253 condemnation parcels; 1457 negotiation parcels) }} \\
\hline LRI & & & & \\
\hline LR test of Independent Eqns. & \multicolumn{4}{|c|}{$11.21>9.21$ ( $\chi^{2}$ at $99 \%$ confidence level with 2 restrictions) } \\
\hline
\end{tabular}

Notes:

$t$-statistics are presented in parentheses.

$\sigma_{i}$ denotes the square-root of the variance of the error terms in the acquisition cost models (3) and (4); $\rho_{i}$ denotes the correlation coefficient between the error terms of the acquisition outcome model (2) and the error terms of the acquisition cost models (3) and (4).

LRI was calculated for the switching regression model $(\ln L=-3314.0)$ versus the constants-only (no-information) model without correlated error terms $\left(\ln L_{0}=-4285.5\right)$ : $\mathrm{LRI}=1-\left(\ln L / \ln L_{0}\right)=0.227$.

“ - " denotes variables that were considered but not statistically significant at the 0.25 level and not included in the final regression models. 
Table 3 Elasticities and Marginal Effects of Various Attributes on Acquisition Costs (\$/sq ft): Negotiation vs. Condemnation

\begin{tabular}{|c|c|c|c|c|c|c|}
\hline $\begin{array}{l}\text { Elasticity/ Marginal } \\
\text { Effects on Cost per } \\
\text { Square Foot }\end{array}$ & Agriculture & Residential & Commercial & Vacant & Other Use & Average \\
\hline \multicolumn{7}{|c|}{ Negotiation Regime (Condemn. = 0) } \\
\hline PopDensity & $0.70 \%$ & $0.70 \%$ & $0.70 \%$ & $0.70 \%$ & $0.70 \%$ & $0.70 \%$ \\
\hline TakenSF & $-0.38 \%$ & $-0.30 \%$ & $-0.24 \%$ & $-0.27 \%$ & $-0.24 \%$ & $-0.28 \%$ \\
\hline RemainderSF & $-0.15 \%$ & $-0.15 \%$ & $-0.11 \%$ & $-0.15 \%$ & $-0.15 \%$ & $-0.14 \%$ \\
\hline Time Trend & $\$ 0.43$ & $\$ 0.98$ & $\$ 3.07$ & $\$ 1.27$ & $\$ 1.91$ & $\$ 1.53$ \\
\hline \multicolumn{7}{|c|}{ Location (TxDOT-defined region [2009]) (Base: North Texas) } \\
\hline Non-North & $-\$ 0.17$ & $-\$ 0.39$ & $-\$ 1.23$ & $-\$ 0.51$ & $-\$ 0.77$ & $-\$ 0.61$ \\
\hline \multicolumn{7}{|c|}{ Taking Type (Base: Partial Taking) } \\
\hline Whole Taking & $\$ 0.37$ & $\$ 0.84$ & $-\$ 3.24$ & $\$ 1.09$ & $\$ 1.68$ & $\$ 0.15$ \\
\hline \multicolumn{7}{|l|}{ Base Case } \\
\hline Cost per sq ft & $\$ 1.83$ & $\$ 4.23$ & $\$ 13.11$ & $\$ 5.40$ & $\$ 8.23$ & $\$ 6.56$ \\
\hline \multicolumn{7}{|c|}{ Condemnation Regime (Condemn. $=1$ ) } \\
\hline PopDensity & $0.54 \%$ & $0.54 \%$ & $0.54 \%$ & $0.54 \%$ & $0.54 \%$ & $0.54 \%$ \\
\hline TakenSF & $-0.48 \%$ & $-0.41 \%$ & $-0.22 \%$ & $-0.38 \%$ & $-0.37 \%$ & $-0.37 \%$ \\
\hline RemainderSF & $-0.09 \%$ & $-0.09 \%$ & $-0.09 \%$ & $-0.09 \%$ & $-0.09 \%$ & $-0.09 \%$ \\
\hline Time Trend & $\$ 0.26$ & $\$ 0.51$ & $\$ 3.26$ & $\$ 0.80$ & $\$ 0.92$ & $\$ 1.15$ \\
\hline \multicolumn{7}{|c|}{ Location (TxDOT-defined region [2009]) (Base: North Texas) } \\
\hline Non-North & - & - & - & - & - & - \\
\hline \multicolumn{7}{|c|}{ Taking Type (Base: Partial Taking) } \\
\hline Whole Taking & $-\$ 0.56$ & $-\$ 1.21$ & $-\$ 8.68$ & $-\$ 1.71$ & $-\$ 2.14$ & $-\$ 2.86$ \\
\hline \multicolumn{7}{|l|}{ Base Case } \\
\hline Cost per sq ft & $\$ 2.12$ & $\$ 4.37$ & $\$ 30.14$ & $\$ 6.49$ & $\$ 8.00$ & $\$ 10.22$ \\
\hline
\end{tabular}

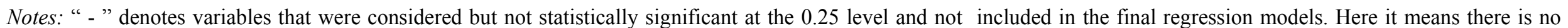
significant difference in acquisition cost (\$/sq ft) among four regions of Texas for condemned parcels, ceteris paribus. 
Table 4 R/W Acquisition Cost Estimates Comparison: Negotiation vs. Condemnation

\begin{tabular}{|c|c|c|c|c|c|}
\hline \multirow{2}{*}{$\begin{array}{c}\text { Acquisition Cost Estimates } \\
\text { Comparison } \\
\text { (Switching Regression ) }\end{array}$} & \multicolumn{4}{|c|}{ Simulation of Betas $(n=1000)$} & \multirow{2}{*}{$\begin{array}{c}\text { Point } \\
\text { Estimate }\end{array}$} \\
\hline & Average & Std. Dev & Min & Max & \\
\hline \multicolumn{6}{|c|}{ Expected Value $^{1}$ of Acquisition Cost } \\
\hline \multicolumn{6}{|l|}{ E(Cost per Square Foot) } \\
\hline Negotiation & $\$ 20.80$ & $\$ 1.30$ & $\$ 17.30$ & $\$ 26.10$ & $\$ 20.70$ \\
\hline Condemnation & $\$ 35.50$ & $\$ 28.50$ & $\$ 3.60$ & $\$ 209.80$ & $\$ 26.60$ \\
\hline$\$$ Increase $^{3}$ in $\mathrm{E}($ Cost $)$ & $\$ 14.70$ & $\$ 28.90$ & $-\$ 18.20$ & $\$ 187.50$ & $\$ 5.90$ \\
\hline \multicolumn{6}{|l|}{ E(Total Cost) } \\
\hline Negotiation & $\$ 266 k$ & $\$ 23.0 \mathrm{k}$ & $\$ 204 k$ & $\$ 351 \mathrm{k}$ & $\$ 263 k$ \\
\hline Condemnation & $\$ 383 \mathrm{k}$ & $\$ 243 k$ & $\$ 63.1 \mathrm{k}$ & $\$ 2.10 \mathrm{M}$ & $\$ 308 \mathrm{k}$ \\
\hline$\$$ Increase in $\mathrm{E}(\mathrm{Cost})$ & $\$ 117 \mathrm{k}$ & $\$ 252 \mathrm{k}$ & $-\$ 223 k$ & $\$ 1.81 \mathrm{M}$ & $\$ 44.9 \mathrm{k}$ \\
\hline \% Increase $\mathrm{I}^{4}$ in $\mathrm{E}(\mathrm{Cost})$ & $77.80 \%$ & $169.10 \%$ & $-87.90 \%$ & $1430.00 \%$ & $21.40 \%$ \\
\hline \% Higher ${ }^{5} \mathrm{E}($ Condemn. Cost $)$ & $57.90 \%$ & $35.90 \%$ & $0.00 \%$ & $100.00 \%$ & $59.30 \%$ \\
\hline \multicolumn{6}{|c|}{ Standard Deviation ${ }^{2}$ of Acquisition Cost } \\
\hline \multicolumn{6}{|c|}{ s.d.(Cost per Square Foot) } \\
\hline Negotiation & $\$ 37.80$ & $\$ 2.70$ & $\$ 30.80$ & $\$ 49.70$ & $\$ 37.50$ \\
\hline Condemnation & $\$ 56.20$ & $\$ 42.00$ & $\$ 7.00$ & $\$ 324.70$ & $\$ 43.20$ \\
\hline \$ Increase in s.d.(Cost) & $\$ 18.40$ & $\$ 41.80$ & $-\$ 33.90$ & $\$ 288.70$ & $\$ 5.70$ \\
\hline \multicolumn{6}{|l|}{ s.d.(Total Cost) } \\
\hline Negotiation & $\$ 483 \mathrm{k}$ & $\$ 40.5 \mathrm{k}$ & $\$ 387 \mathrm{k}$ & $\$ 643 k$ & $\$ 477 \mathrm{k}$ \\
\hline Condemnation & $\$ 612 k$ & $\$ 359 \mathrm{k}$ & $\$ 121 \mathrm{k}$ & $\$ 3.34 \mathrm{M}$ & $\$ 501 \mathrm{k}$ \\
\hline \$ Increase in s.d.(Cost) & $\$ 129 \mathrm{k}$ & $\$ 363 \mathrm{k}$ & $-\$ 382 k$ & $\$ 2.84 \mathrm{M}$ & $\$ 24.1 \mathrm{k}$ \\
\hline \% Increase in s.d.(Cost) & $51.10 \%$ & $131.70 \%$ & $-86.70 \%$ & $1326.10 \%$ & $8.90 \%$ \\
\hline \% Higher s.d.(Condemn. Cost) & $51.20 \%$ & $35.00 \%$ & $0.00 \%$ & $100.00 \%$ & $50.50 \%$ \\
\hline
\end{tabular}

Notes:

1, 2. Expected value (E) and standard deviation (s.d.) of acquisition costs were calculated as followed:

$$
\begin{aligned}
& \mathrm{E}\left(Y_{i}\right)=\mathrm{E}\left(\mathrm{e}^{x_{j i}^{\prime} \beta_{j}+\varepsilon_{j i}}\right)=\mathrm{e}^{x_{j i}^{\prime} \beta_{j}} \mathrm{E}\left(\mathrm{e}^{\varepsilon_{j i}}\right)=\mathrm{e}^{x_{j i}^{\prime} \beta_{j}} \mathrm{e}^{\sigma_{j}^{2} / 2} \quad j=1,2 . \\
& \text { s. d. }\left(Y_{i}\right)=\sqrt{\operatorname{Var}\left(Y_{i}\right)}=\sqrt{\operatorname{Var}\left(\mathrm{e}^{x_{j i}^{\prime} \beta_{j}+\varepsilon_{j i}}\right)}=\mathrm{e}^{x_{j i}^{\prime} \beta_{j}+\sigma_{j}^{2} / 2} \sqrt{\mathrm{e}^{\sigma_{j}^{2}}-1} \quad j=1,2 .
\end{aligned}
$$

where $j=1,2$ represents condemnation and negotiation regime, respectively.

3. "\$ Increase" measures the increase in expected value (or standard deviation) of acquisition cost (per square foot or in total) when a parcel is acquired by condemnation instead of negotiation.

4. " \% Increase" measures the percentage increase in expected value (or standard deviation) of acquisition cost (per square foot or in total) when a parcel is acquired by condemnation instead of negotiation.

5. " \% Higher" represents the percentage of the parcels which have higher expected value (or standard deviation) of acquisition cost (per square foot or in total) when acquired by condemnation compared with negotiation. 
Table 5 Application of Switching Regression Model Prediction for 9-parcel Corridor in Brazoria County (Houston)

\begin{tabular}{|c|c|c|c|c|c|c|c|c|c|c|}
\hline $\begin{array}{l}\text { Property } \\
\text { Description }\end{array}$ & Parcel \#: 1 & 2 & 3 & 4 & 5 & 6 & 7 & 8 & 9 & $\begin{array}{c}\text { Total } \\
\text { Cost }\end{array}$ \\
\hline $\begin{array}{l}\text { Taken Area } \\
\text { (square feet) }\end{array}$ & 601 & 366 & 349 & 1,494 & 2,472 & 4,648 & 4,508 & 11,892 & 6,591 & \\
\hline Acquisition Year & 2009 & 2009 & 2008 & 2009 & 2009 & 2009 & 2008 & 2009 & 2008 & \\
\hline Property Use & Vacant Lot & Commercial & Service Station & Commercial & Commercial & Commercial & Retail Store & Commercial & Retail Store & \\
\hline PartialTaking & 1 & 1 & 1 & 1 & 1 & 1 & 1 & 1 & 1 & \\
\hline $\begin{array}{l}\text { Remainder } \\
\text { (square feet) }\end{array}$ & 54,450 & 277,804 & 18,382 & 42,210 & 52,468 & 701,926 & 58,458 & 854,081 & 86,075 & \\
\hline Ownership & Individual & $\begin{array}{c}\text { Limited } \\
\text { Partnership }\end{array}$ & $\begin{array}{c}\text { Limited } \\
\text { Partnership }\end{array}$ & $\begin{array}{c}\text { Limited } \\
\text { Partnership }\end{array}$ & Individual & Corporation & Corporation & $\begin{array}{c}\text { Limited } \\
\text { Partnership }\end{array}$ & Corporation & \\
\hline $\begin{array}{l}\text { Prob } \\
(\text { Condemn. }=1)\end{array}$ & $\begin{array}{c}11.5 \% \\
(11.4 \%)\end{array}$ & $\begin{array}{c}15.0 \% \\
(14.8 \%)\end{array}$ & $\begin{array}{c}20.7 \% \\
(20.5 \%)\end{array}$ & $\begin{array}{c}25.4 \% \\
(25.1 \%)\end{array}$ & $\begin{array}{c}23.3 \% \\
(23.0 \%)\end{array}$ & $\begin{array}{c}23.4 \% \\
(23.1 \%)\end{array}$ & $\begin{array}{c}30.1 \% \\
(29.8 \%)\end{array}$ & $\begin{array}{c}27.5 \% \\
(27.2 \%)\end{array}$ & $\begin{array}{c}31.0 \% \\
(30.7 \%)\end{array}$ & \\
\hline $\begin{array}{l}\text { Acquisition } \\
\text { Type }^{1}\end{array}$ & 0 & 1 & 0 & 0 & 1 & 1 & 1 & 0 & 1 & \\
\hline $\begin{array}{l}\mathrm{E}[\text { Cost }]^{2} \\
(\text { Condemn. }=0)\end{array}$ & $\begin{array}{c}\$ 6,312 \\
(\$ 6,278)\end{array}$ & $\begin{array}{c}\$ 8,126 \\
(\$ 8,033)\end{array}$ & $\begin{array}{c}\$ 10,495 \\
(\$ 10,381)\end{array}$ & $\begin{array}{c}\$ 24,242 \\
(\$ 24,072)\end{array}$ & $\begin{array}{c}\$ 33,015 \\
(\$ 32,798)\end{array}$ & $\begin{array}{c}\$ 39,218 \\
(\$ 38,894)\end{array}$ & $\begin{array}{c}\$ 45,411 \\
(\$ 45,049)\end{array}$ & $\begin{array}{c}\$ 71,182 \\
(\$ 70,640)\end{array}$ & $\begin{array}{c}\$ 55,770 \\
(\$ 55,324)\end{array}$ & \\
\hline $\begin{array}{l}\mathrm{E}[\text { Cost }] \\
(\text { Condemn. }=1)\end{array}$ & $\begin{array}{c}\$ 17,474 \\
(\$ 10,802)\end{array}$ & $\begin{array}{c}\$ 26,232 \\
(\$ 17,818)\end{array}$ & $\begin{array}{c}\$ 34,569 \\
(\$ 25,105)\end{array}$ & $\begin{array}{c}\$ 82,649 \\
(\$ 60,851)\end{array}$ & $\begin{array}{l}\$ 116,632 \\
(\$ 87,108)\end{array}$ & $\begin{array}{c}\$ 150,345 \\
(\$ 110,664)\end{array}$ & $\begin{array}{c}\$ 183,240 \\
(\$ 142,178)\end{array}$ & $\begin{array}{c}\$ 291,416 \\
(\$ 220,270)\end{array}$ & $\begin{array}{c}\$ 233,123 \\
(\$ 182,115)\end{array}$ & \\
\hline $\begin{array}{l}\text { Weighted Cost } \\
\text { Estimate }^{3}\end{array}$ & $\begin{array}{c}\$ 7,601 \\
(\$ 6,796)\end{array}$ & $\begin{array}{l}\$ 10,843 \\
(\$ 9,479)\end{array}$ & $\begin{array}{c}\$ 15,485 \\
(\$ 13,402)\end{array}$ & $\begin{array}{c}\$ 39,053 \\
(\$ 33,306)\end{array}$ & $\begin{array}{c}\$ 52,458 \\
(\$ 45,264)\end{array}$ & $\begin{array}{c}\$ 65,252 \\
(\$ 55,479)\end{array}$ & $\begin{array}{c}\$ 86,909 \\
(\$ 74,011)\end{array}$ & $\begin{array}{c}\$ 131,786 \\
(\$ 111,275)\end{array}$ & $\begin{array}{l}\$ 110,767 \\
(\$ 94,255)\end{array}$ & $\begin{array}{c}\$ 520,154 \\
(\$ 443,268)\end{array}$ \\
\hline Actual Cost & $\$ 5,248$ & $\$ 7,718$ & $\$ 21,083$ & $\$ 22,760$ & $\$ 66,887$ & $\$ 88,110$ & $\$ 107,664$ & $\$ 122,476$ & $\$ 235,836$ & $\$ 677,782$ \\
\hline $\begin{array}{l}\text { Percent } \\
\text { Difference }\end{array}$ & $\begin{array}{c}44.8 \% \\
(29.5 \%)\end{array}$ & $\begin{array}{c}40.5 \% \\
(22.8 \%)\end{array}$ & $\begin{array}{c}-26.6 \% \\
(-36.4 \%)\end{array}$ & $\begin{array}{c}71.6 \% \\
(46.3 \%)\end{array}$ & $\begin{array}{c}-21.6 \% \\
(-32.3 \%)\end{array}$ & $\begin{array}{l}-25.9 \% \\
(-37.0 \%)\end{array}$ & $\begin{array}{l}-19.3 \% \\
(-31.3 \%)\end{array}$ & $\begin{array}{l}7.6 \% \\
(-9.1 \%)\end{array}$ & $\begin{array}{l}-53.0 \% \\
(-60.0 \%)\end{array}$ & $\begin{array}{l}-23.3 \% \\
(-34.6 \%)\end{array}$ \\
\hline
\end{tabular}

Notes:

Point Estimates are presented as italicized values in parentheses.

1. Acquisition Types 1 and 0 represent condemnation and negotiation, respectively.

2. The Expected value (E) of acquisition costs were calculated as noted for Table 4.

3. The weights for cost estimates of condemnation and negotiation here are their estimated probability of being true, respectively, expressed as:

Weighted Cost $=\operatorname{Pr}($ Condemn. $=1) \cdot E[$ Cost $\mid$ Condemn. $=1]+\operatorname{Pr}($ Condemn. $=0) \cdot E[$ Cost $\mid$ Condemn. $=0]$. 
Table 6 OLS Regression Results for Duration (Time till Acquisition)

\begin{tabular}{|c|c|c|c|c|c|c|c|}
\hline $\begin{array}{l}\text { Dependent Variable: } \\
\text { Number of Obs. } \\
\text { Adjusted R-square }\end{array}$ & $\begin{array}{r}\ln (\mathrm{L} \\
96 \\
0.34 \\
\end{array}$ & ation) & & & & & \\
\hline \multicolumn{3}{|c|}{$\begin{array}{c}\text { OLS Regression } \\
\end{array}$} & \multicolumn{5}{|c|}{ Elasticities and Marginal Effects } \\
\hline \multirow[b]{2}{*}{ Variables } & \multirow[b]{2}{*}{ Coef. } & \multirow[b]{2}{*}{ p-value } & \multicolumn{4}{|c|}{ Simulation Estimate $(\mathrm{n}=1000)$} & \multirow{2}{*}{$\begin{array}{c}\text { Point } \\
\text { Estimate }\end{array}$} \\
\hline & & & Average & $\begin{array}{c}\text { Std. } \\
\text { Dev. }\end{array}$ & Min & Max & \\
\hline (Constant) & 4.353 & 0.000 & & & & & \\
\hline TimeTrend & -0.141 & 0.000 & $-14 d$ & $4 \mathrm{~d}$ & $-27 d$ & $-3 d$ & $-14 d$ \\
\hline PopDensity & $1.56 \mathrm{E}-04$ & 0.000 & $0.124 \%$ & $0.024 \%$ & $0.059 \%$ & $0.205 \%$ & $0.124 \%$ \\
\hline \multicolumn{8}{|l|}{ Parcel Size } \\
\hline $\ln ($ TakenSF) & 0.026 & 0.028 & $0.026 \%$ & $0.012 \%$ & $-0.009 \%$ & $0.065 \%$ & $0.026 \%$ \\
\hline $\ln ($ RemainderSF) & 0.034 & 0.000 & $0.034 \%$ & $0.005 \%$ & $0.015 \%$ & $0.050 \%$ & $0.034 \%$ \\
\hline \multicolumn{8}{|c|}{ Land Use Types (Base: Agriculture) } \\
\hline Residential & -0.087 & 0.150 & $-9 d$ & $7 \mathrm{~d}$ & $-31 d$ & $9 \mathrm{~d}$ & $-9 d$ \\
\hline Commercial & 0.260 & 0.000 & $33 \mathrm{~d}$ & $8 \mathrm{~d}$ & $8 \mathrm{~d}$ & $57 \mathrm{~d}$ & $33 \mathrm{~d}$ \\
\hline Vacant & - & - & & & & & \\
\hline OtherUse & 0.186 & 0.037 & $22 \mathrm{~d}$ & $12 \mathrm{~d}$ & $-18 d$ & $58 \mathrm{~d}$ & $22 \mathrm{~d}$ \\
\hline \multicolumn{8}{|c|}{ Location (Base: North Texas) } \\
\hline West & -0.187 & 0.133 & $-18 d$ & $11 \mathrm{~d}$ & $-66 \mathrm{~d}$ & $17 \mathrm{~d}$ & $-19 d$ \\
\hline South & - & - & & & & & \\
\hline East & 0.146 & 0.045 & $17 \mathrm{~d}$ & $10 \mathrm{~d}$ & $-5 d$ & $50 \mathrm{~d}$ & $17 \mathrm{~d}$ \\
\hline \multicolumn{8}{|c|}{ Ownership Type (Base: All other Types) } \\
\hline $\begin{array}{l}\text { Corporation } \\
\text { Individual }\end{array}$ & $\begin{array}{c}0.163 \\
-\end{array}$ & $\begin{array}{c}0.001 \\
-\end{array}$ & $20 \mathrm{~d}$ & $7 \mathrm{~d}$ & $-1 d$ & $39 \mathrm{~d}$ & $19 \mathrm{~d}$ \\
\hline \multicolumn{8}{|l|}{ Possession Type } \\
\hline \multirow[t]{2}{*}{ Condemnation } & 1.094 & 0.000 & $219 \mathrm{~d}$ & $26 \mathrm{~d}$ & $144 \mathrm{~d}$ & $309 \mathrm{~d}$ & $217 \mathrm{~d}$ \\
\hline & & Base Case* & $110 \mathrm{~d}$ & $8 \mathrm{~d}$ & $81 \mathrm{~d}$ & $136 \mathrm{~d}$ & $109 \mathrm{~d}$ \\
\hline
\end{tabular}

Notes:

Elasticities and marginal effects measures were computed for continuous variables and indicator variables, respectively. Elasticity measures the percentage change in acquisition duration (days) associated with a one-percentage-point change in the covariate $\mathrm{X}_{k}$, expressed as follows:

$$
\text { Elasticity }=\frac{\partial \log (\text { Duration })}{\partial \log x_{k}}
$$

Marginal effect measures the change in acquisition duration (days) associated with a discrete change of indicator variable $X_{k}$ from 0 to1, expressed as:

Marginal Effect (days) $=\left[\right.$ Duration (days) $\left.\mid x_{k}=1, x_{*}\right]-\left[\right.$ Duration (days) $\left.\mid x_{k}=0, x_{*}\right]$.

where $x_{*}$ represents the base case ${ }^{*}$, which is in agricultural use in Texas' northern region with a (sample-) average population density of 796 persons per square mile, acquired by negotiation. It entails a whole (rather than partial) taking type of (sample-) average size (49,400 square feet [1.13 acres] of land) with other ownership type, such as government agencies, utility companies and Trusts (rather than the individual- or corporation-ownership-type).

“ - " denotes variables that were considered but not statistically significant at the 0.25 level and not included in the final regression models. Here, it means the acquisition durations for vacant and individually owned parcels are not significantly different from those of agriculture use and all other non-corporation ownership type parcels, respectively, ceteris paribus. 